\title{
EXAMINING THE VELOCITY- AND TIME-DEPENDENT FRICTION IN CASE OF STEEL AND POLYAMIDE
}

\author{
Author(s): \\ A. Csatár ${ }^{1}-$ F. Safranyik ${ }^{2}$ \\ Affiliation: \\ 1Scientific Deputy General Director, Hungarian Institute of Agricultural Engineering \\ ${ }^{2}$ Szent István University, Faculty of Mechanical Engineering, Department of Mechanics and Technical Drawing \\ Email address: \\ csatar.attila@gek.szie.hu, safranyik.ferenc@hallgato.szie.hu
}

\begin{abstract}
The phenomenon of friction reduces the efficiency of almost all machines in practice. For reduce the deficits we have to understand this phenomenon and we have to take it in all cases into consideration during design. Nevertheless in certain cases the describing of a friction process is very difficult; because this depends on a lot of parameters. In case of polymers, granular materials or in geology the rate- and state dependent friction have great importance. In this paper velocity- and time dependent friction of polyamide and steel is examined with the help of a direct shear apparatus, which was developed in our earlier work. Based on the results of experimental measurements the previously developed apparatus is suitable for examine time dependent properties of friction.
\end{abstract}

\section{Keywords}

friction, time-dependence, velocity-dependence

\section{Introduction}

The friction process was examined first almost three centuries ago by Coulomb [5] and it was discovered that the kinetic friction does not depend on the shear velocity. Later with more precise experiments showed that this phenomenon depends on a lot of parameters, such as materials, roughness, temperature or the shear velocity. Due to the diverse parameters the description of a friction process is very difficult in certain cases. In geology, mining- and earthquake science, in case of polymers, granular materials or other special materials the time- and velocitydependent friction (creep and relaxation) have great importance and only few researchers investigate the thermodynamic aspects of this time dependence of friction $[6,7,8]$. The aim of our work is to examine the velocity dependent friction of polyamide and steel and the revise of the previously by our developed direct shear testing apparatus.

\subsection{Friction test}

The knowledge on the shear strength is very important in description of a friction process. This parameter means the relationship between the displacement and the shear force and a lot of parameters have influence on this [1]. The shear strength can be evaluated by using direct shear test; in course of this the surfaces are pressed together with constant normal load meanwhile moving on each other. During the shear process, the shear force is measured as function of displacement. The material properties, the roughness and the shear velocity have great influence on shear strength [1].

During the direct shear test of two smooth surfaces (under constant normal load and constant shear velocity) the shear strength increases to an initial peak, which is followed by slowly displacement weakening and then stabilization at a residual shear strength, which does not change or increases very slowly with additional displacement [1].

Based on shear tests with different normal loads, the shear strength is in linear correlation with normal strength. The slope of this line is the friction coefficient concerning to the materials, the designate constant of this line is the cohesion between the surfaces. The shear strength is based on the Mohr-Coulomb equation [5]:

$$
\tau(\phi)=c+\sigma_{n} \cdot \operatorname{tg} \phi,
$$

where $\mathrm{c}$ is the cohesion, is the friction angle between the surfaces.

The residual strength is [5]:

$$
\tau(\phi)=\sigma_{n} \cdot \operatorname{tg} \phi_{r}
$$

where is the residual friction angle between the surfaces.

\subsection{Time- and velocity-dependent experiments}

The time- and velocity-dependent friction have great importance in geology: faults may undergo decelerating postseismic slip (afterslip), long term stable slip (fault creep) in the absence of earthquake instability, and perhaps slow postseismic slip [2]. For this reason Dietrich et al. made laboratory shear experiments with clean surfaces of granite $[3,4]$ and with a layer of simulated fault gouge consisting of crushed and sieved granite [2]. These experiments were made with different shear parameters (normal load, shear velocity). The sample assembly consists of a three blocks, sandwich type direct shear configuration (Fig. 1.).

Three different types of tests were made: constant velocity, multiple velocity and time dependence shear tests. The constant velocity tests were made at $2.5 \mu \mathrm{m} / \mathrm{s}$ (Fig. 2/a). In the multiply- 
velocity tests the shear velocity was constant for a predeterminated displacement, then suddenly changed by a factor of 10, held constant for another displacement then changed again and so on (Fig. 2/b). The third group of shear test was the timedependence tests, in which constant velocity shear was interrupted at a specified displacement where the control displacement is held at zero for a specified time interval (Fig. 2/c) [2].

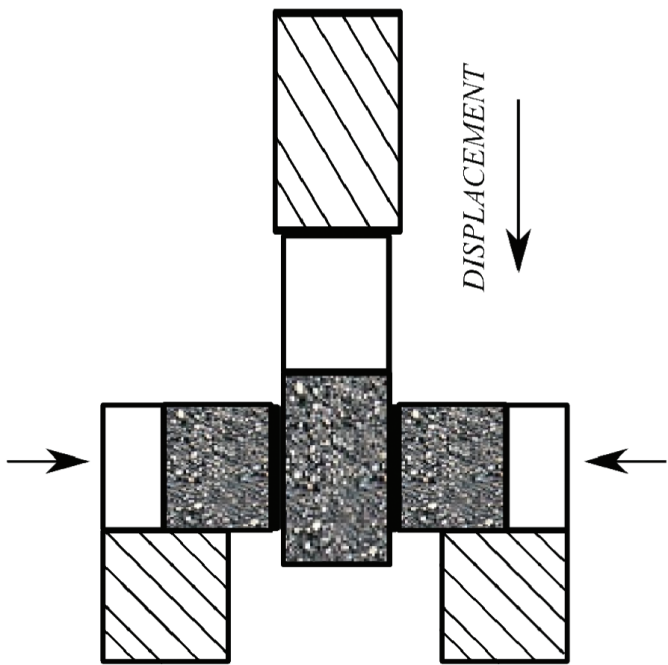

Figure 1. The sample assembly by Dietrich [2]

The aim of the constant velocity tests were to examine the overall form of stress-displacement curves (Fig. 2/d) to permit reasonably direct comparison to be made for the control of strength by the fault parameters. Based on these curves the shear strength increases to an initial peak, which is followed by a slow displacement weakening and then stabilization at residual shear strength (Fig. 2/d). If the shear stress cycling to zero after reaching residual strength, acts to restore the peak in the stressdisplacement curves. This cycling increases the total displacement and also the peak and residual strength [2].

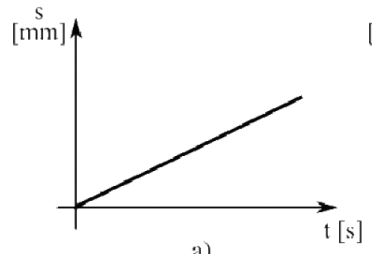

a)
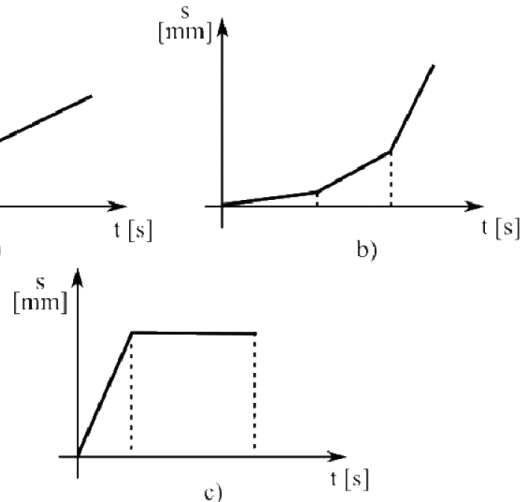
$[\mathrm{s}]$

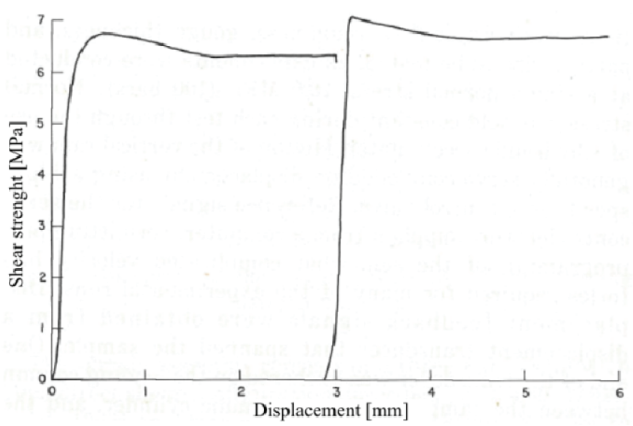

e)

Figure 2. a) Constant velocity test; b) Multiply velocity-test; c) Time dependence test; d) Shear diagram with constant velocity and normal stress [2]

The purpose of the multiply-velocity tests was to look for variations of strength as a function of velocity. A step increase of shear velocity results an immediate jump in frictional coefficient followed by displacement dependent decay and stabilization at a new steady-state friction. The reverse is seen if the shear speed is decreased (Fig. 3.) [3].

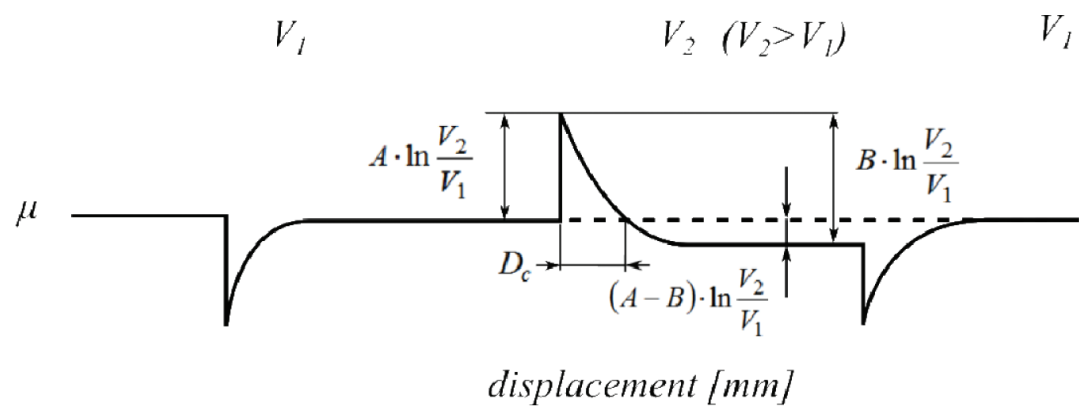

Figure 3. Effect of steps in shear speed on a friction coefficient, the case of velocity weakening [3]

Dietrich and Kilgore [3] made a shear rate- and state-dependent constitutive formulation for fault tests. This formulation provides a descriptive framework for the interpretation of the transient shearing phenomenon. The coefficient of friction can be represented [3]:

$$
\mu=\frac{\tau}{\sigma}=\mu_{0}+A \cdot \ln \left(\frac{V}{V^{*}}+1\right)+B \cdot \ln \left(\frac{\Theta}{\Theta^{*}}+1\right)
$$

where and are shear and normal stress $\mathrm{V}$ is a shear speed and is a state variable. Parameters, A and B are experimentally determined constants and $\mathrm{V}^{*}$ and are normalizing constants [3].

\subsection{The developed shear testing apparatus}

The design of our test apparatus was made on the basis of Dietrich's vertical shear tester [2]. In case of Dietrich's arrangement the displacement was vertical and the normal force was horizontal, while in our case the normal force is provided by an INSTRON 5581 type universal material testing machine, so it should be vertical thus the displacement must be horizontal. The shear force was measured by a load cell which is at the holding point of the fixed part; the displacement was measured by an inductive displacement transducer at the moving part. The displacement provided by a stepper motor (Fig. 4.). 


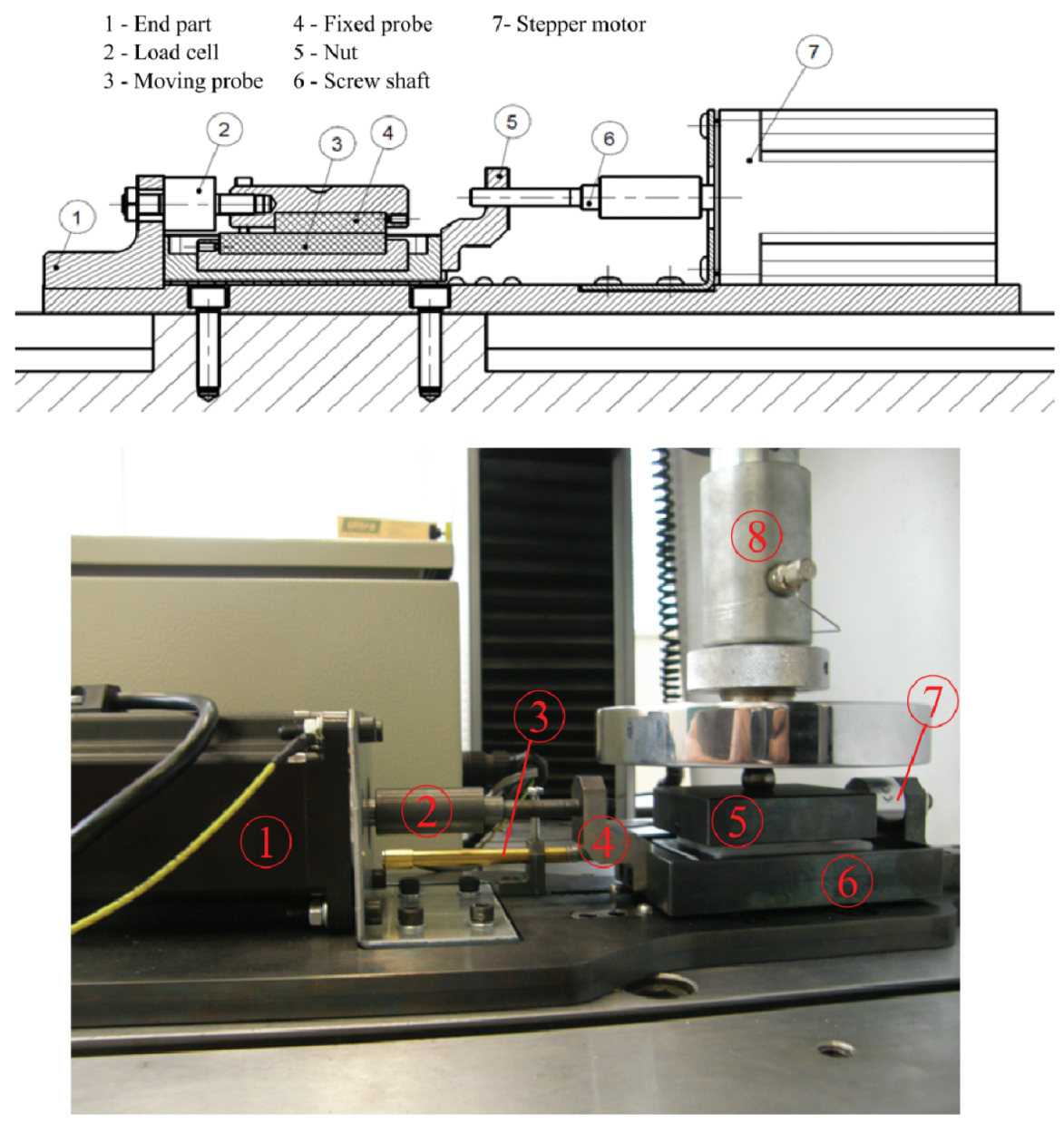

Figure 4 . The test assembly and the finished apparatus

On Fig. 4 the finished shear apparatus can be seen: $1-$ stepper motor; 2 - screw shaft and cased coupling; 3 - displacement transducer; 4 - nut; 5 - fixed part; 6 - moving part; 7 - load cell; 8 - INSTRON 5581. The normal load was provided by the INSTRON 5581 type universal material testing machine the load was transferred trough a steel ball that ensures the punctual load to the fixed part.

The chosen motor is a three phase stepper motor that divides a full rotation into a number of equal steps; therefore in order to achieve the minimum speed a XINJE DP-7022 digital stepper drive was used. With its microstep function no more than 65535 step/rotation can be set up which ensures the low and exact angular velocity of the stepper motor. Microstepping is a way of moving a stepper smoothly. The measurement system of the appliance is a separate module. The displacement is measured by an HBM WETA 1/10 inductive economic displacement transducer, the shear force by an HBM U9B $5 \mathrm{kN}$ force transducer. The Spider 8 and the Catman 4.5 software carry out the data acquisition. [9]

\section{Experimental measurements and results}

Experimental measurements were carried out with polyamide and steel probes. The usual experimental protocol for evaluating slip rate and state dependence of friction of changing the shear velocity in a stepwise manner under of constant normal stress. Normal stress was held constant during the measurements which were ensured by the force regulated INSTRON 5581 universal material testing machine. Multiple velocity tests were carried out with constant shear velocity for a predetermined displacement, then suddenly changed by a factor of 10 , then held constant for another displacement and changed back to the first velocity. The tests were carried out with two different speed levels, 2 and 4 $\mu \mathrm{m} / \mathrm{s}$, for both materials. Additionally two different normal stress levels were investigated, 20 and $40 \mathrm{kPa}$. During the tests the shear force and the displacement were measured and the shear diagrams were determined (Fig. 5.).

The purpose of these multiple-velocity tests was to look the time dependent friction coefficient as seen in the earlier rock friction experiments of Dietrich $[2,4,6]$. In these earlier works two different velocity effects was observed, the step increase of shear velocity results in an immediate jump in frictional coefficient followed by displacement dependent decay and stabilization at a new steady-state friction. The reverse is seen if the shear speed is decreased. This friction coefficient jump on the higher speed level and the decrease on lower speed level can be seen on the shear diagrams (Fig. 5.).

Step changes of velocity results residual and transient changes in friction coefficient. Firstly at constant sliding velocity has proceeded for a sufficient distance for $\mu$ to have stabilized at a residual value $(\mu 1)$ then due to the suddenly increase of velocity produces an immediate increase in friction coefficient then this followed by a decrease $(\mu 2)$ to a new residual value. This new residual value is generally less than the residual coefficient on the previous slower velocity phase. After predetermined sliding displacement the shear velocity abruptly decrease to the previously lower level results a positive jump in the friction coefficient to a new residual value $(\mu 3)$, which is greater than the residual coefficient at the first phase of the test with the same sliding velocity. 

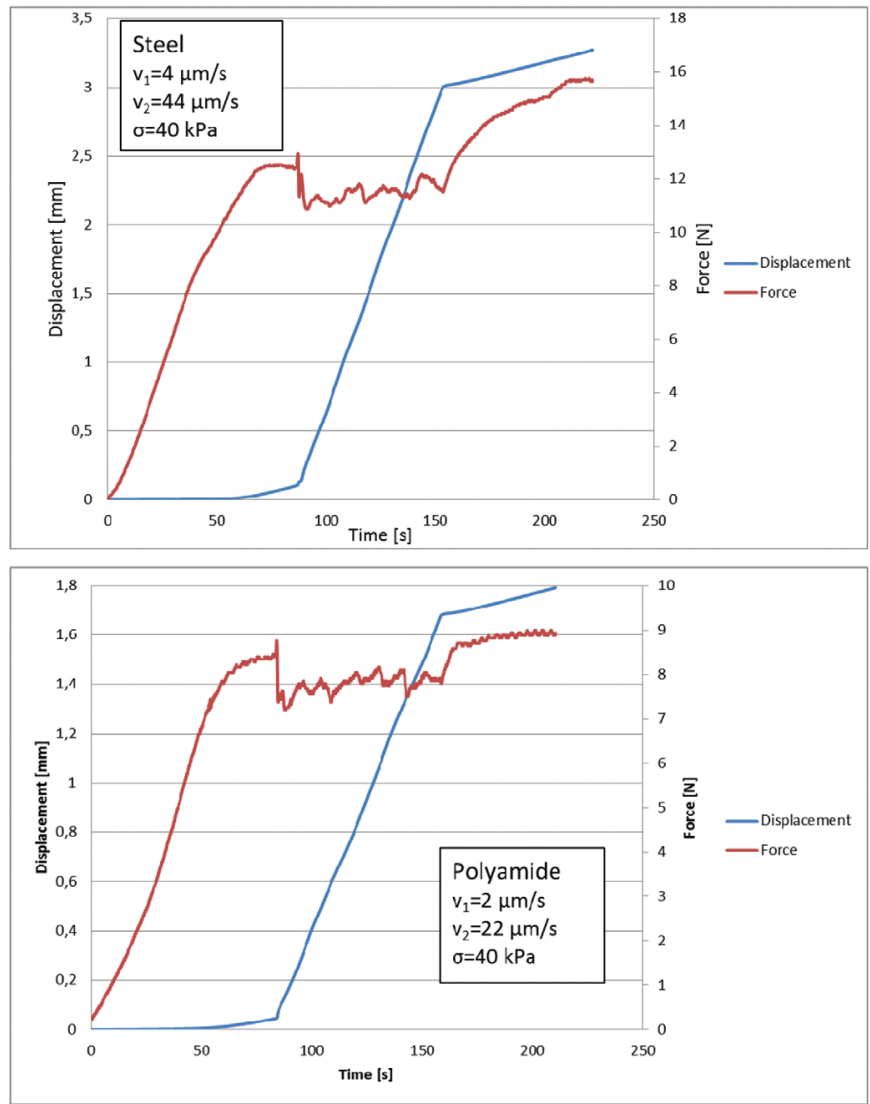

Figure 5. Displacement in function of time
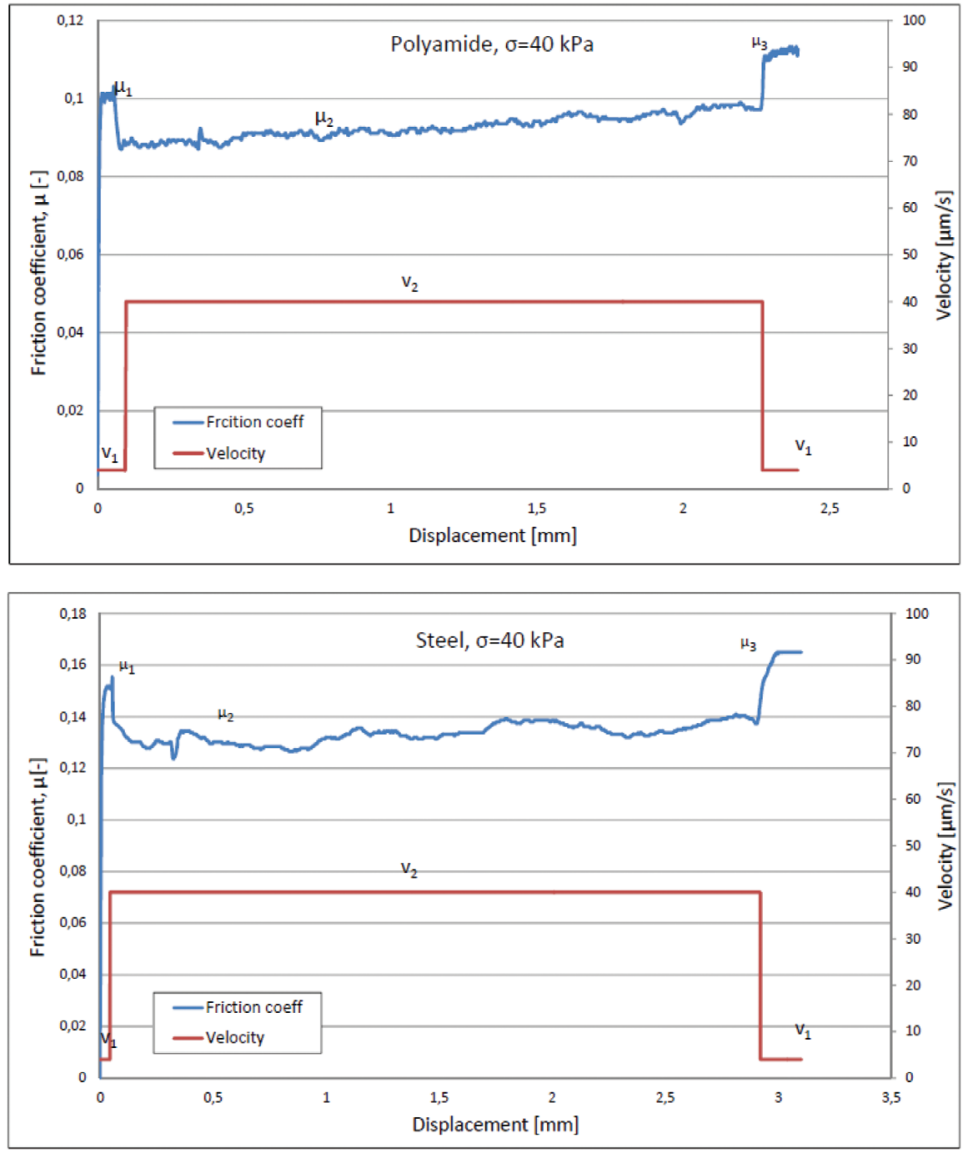

Figure 6. Friction coefficient versus displacement 


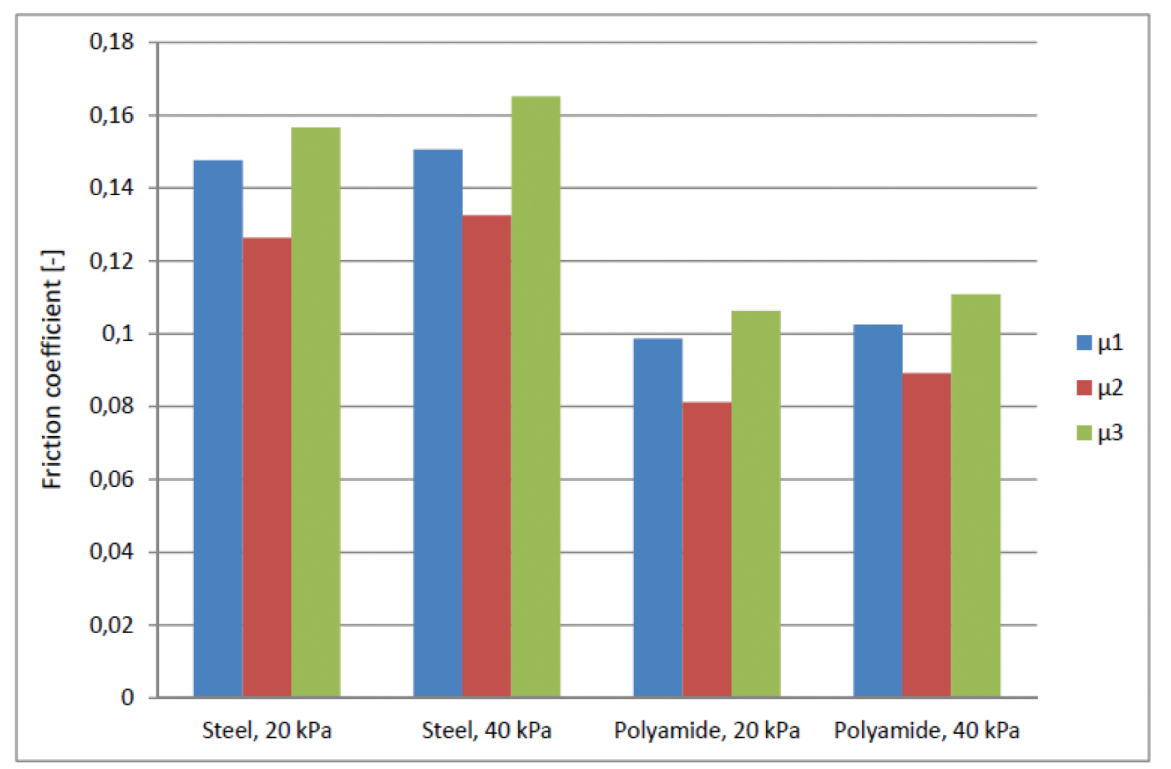

Figure 7. The changes of residual strengths in case of different normal stress

Based on the different measurements determinable that the $\mu 1$, $\mu 2, \mu 3$ values depend on the normal stress and the material. In case of rigid materials (steel) the residual friction coefficient decrease and increase are greater than a less rigid material (polyamide). Based on these observation verifiable that our shear apparatus (which based on Dietrich's work) is suitable for examine the time- and velocity-dependence of friction.

\section{Summary}

We have developed a simple experimental device for testing timeand velocity dependent properties of friction. The first measurements were performed with poliamid and steel. They show velocity weakening and stick-slip phenomena at the higher velocity level for both materials. Therefore we have demonstrated, that the apparatus is able to reproduce several important time dependent friction phenomena and therefore it is suitable for experimental investigations. We have also investigated effects related to shear strhength.

\section{Acknowledgment}

This paper was supported by the János Bolyai Research Scholarschip of the Hungarian Academy of Sciences.

\section{References}

[1] Asszonyi, Cs., Kertész, P., Richter, R.: A kőzetmechanika anyagszerkezeti és reológiai alapjai, Veszprémi Akadémiai Bizottság, Veszprém, 1980, pp. 446.
[2] Dietrich, J. H.: Constitutive properties of faults with simulated gouge, Geophysical Monograph Series, Vol. 24, 1981, p. $103-120$.

[3] Dietrich, J. H., Kilgore, B. D.: Direct observation of frictional contacts: New insights for state-dependent properties, Pure and Applied Geophysics PAGEOPH, Vol. 143, 1994, p. 283302.

[4] Dietrich, J. H.: Modeling of Rock Friction I.: Experimental Results and Constitutive Equations, Journal of Geophysical Research, Vol. 84, 1979, p. 2161-2168.

[5] Dowson, D.: History of tribology, Longman, New York, 1979. [6] Ruina, A. L.: Slip Instability and State Variable Friction Laws, Journal of Geophysical Research, Vol. 88, 1983, p. 1035910370.

[7] N. Mitsui and P. Ván: Thermodynamic aspects of rock friction, Acta Geodaetica et Geophysica, Vol. 49, 2014, p.135146, (arXiv:1312.4930 [physics.geo-ph])

[8] Ván P.: A képlékenység termodinamikája. In: Fülöp T. (szerk.) Idő és térderiváltak anyagtörvényekben. Mérnökgeológia-Kőzetmechanika Kiskönyvtár 10, Műegyetemi Kiadó, Budapest, 2010, pp. 15-50.

[9] A. Csatár; F. Safranyik; G. Bércesi: A NEW direct shear testing apparatus for the examination of the velocity- and timedependent friction, Hungarian Agricultural Engineering 25; p. 54-58; (ISSN 0864-7410) 